
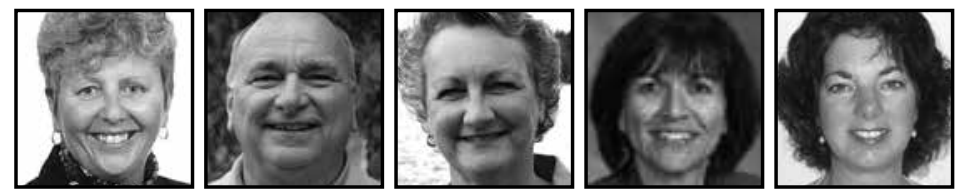

\title{
Developing Multi-Agency Partnerships for Early Learning: Seven Keys to Success
}

\author{
Susan E. Elliott-Johns, Ron Wideman, Glenda L. Black, \\ Maria Cantalini-Williams, and Jenny Guibert, Nipissing University
}

\section{ABSTRACT}

The ongoing emphasis on early years education in Ontario provided a rich context for this research project, commissioned by The Learning Partnership (TLP), to evaluate a new provincial project called FACES (Family and Community Engagement Strategy). This initiative seeks to extend and enhance community-based, multi-agency partnerships that support young children and their families in successful transitions to school. Interview data from individuals and focus groups suggest re-thinking early childhood education practices to include innovative multi-agency, community-based partnerships. "Seven Keys to Success" in building multi-agency partnerships emerged from the data providing direction for educators and policy makers.

\section{Introduction}

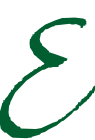

ffective transitions to school for young children and their families involve a complex range of knowledge, skills, aptitudes, and attitudes in differing community contexts. In an earlier study, Campbell, Elliott-Johns, and Wideman $(2008,2010$, identified six mutually supportive and essential keys to the success of a multi-agency project, "Welcome to Kindergarten" (WTK), a project seen to generate high levels of community participation and commitment. The WTK partnership project in North Bay focused on preparing children for the transition to Kindergarten. Both the WTK project and the research conducted were funded by The Learning Partnership (TLP), which sponsors WTK nationally. 
As a brief backgrounder, six keys to success were identified in the initial study as assisting in creating and maintaining an active partnership project among independent community agencies: 1) the community had already identified early literacy learning as a priority; 2 ) it involved itself voluntarily in the project because it saw WTK as a potential source of help in addressing the problem identified; 3 ) the project was treated as a creative partnership among TLP and the local agencies; 4) there was significant scope for local leaders to shape the project to meet the needs of the community as well as the requirements of TLP; 5 ) there was a strong spirit of collaboration among all the partners, and; 6) collaboration among partners was grounded in trusting relationships that facilitated informal inter-organizational action.

The initial study also concluded that high levels of community participation and commitment generated in the North Bay multi-agency partnerships were the result of an alignment of these six keys. While the existence of committed and capable leadership was clearly identified, authentic, shared, and responsive leadership (Begley, 2001) also played an essential role in the development of all six keys by creating vision, developing widespread understanding and agreement, mobilizing resources, and building relationships. Shared leadership between TLP and participants in the agencies was devoted to a common cause. Furthermore, partnership, trust, collective purpose, and community efficacy resulted in coordinated and widespread collective action and the promotion of early learning as a shared endeavour.

Building on the previous study, in 2010 TLP sponsored "Family and Community Engagement Strategy (FACES)" and supported the work of multi-agency projects in three geographically and economically diverse communities in Ontario. The three sitebased projects were evaluated over two years and some of the results, including how the six keys to success identified in the earlier study also pertained to these three cases, are presented. (Note: The term "community agency" is used to describe a variety of service providers including: child care; community living; best start network; children's treatment; early years; parent resource; developmental services; public libraries; public health; and district school boards).

\section{Background to the Current Study (Evaluation of FACES)}

TLP describes itself as a "national not-for-profit organization dedicated to championing a strong public education system in Canada through innovative programs, credible 
research, policy initiatives, executive leadership, and public engagement" (http://www. thelearningpartnership.ca/files/download/e12171144a2f686) and the overall goal of FACES was described as follows:

to develop a coordinated community-based model that will strengthen and extend the Welcome to Kindergarten program's engagement of families in early learning activities. The goal of FACES is to enhance each community's ability to support families and young children during the transition to school. (http://www.tlpcanada.ca/ page.aspx?pid=692)

Consistent with this broadly stated goal, each of the three communities involved committed to work with TLP for three years to develop a coordinated, community-based FACES model, one seen as sustainable within the situated context of the community. Thus, supported by TLP, each community had its own FACES coordinator, established its own multi-agency steering committee with two co-chairs, and initiated activity in a number of schools or community hubs.

In forging the partnership between TLP and the three communities, there was agreement that each of the three FACES projects would be evaluated as it developed. The purpose of the evaluation was to tell the stories and celebrate the accomplishments of the three communities, individually and collectively, as they worked toward the FACES goals, with the intention of sharing their experience with other communities interested in establishing their own FACES projects. The goal of the evaluation was not to judge individual community agencies, school boards, schools, educators, or parents, but rather to analyze the impact of FACES processes and activities.

\section{Contextualizing the Research in the Literature}

A review of literature pertinent to community development, early learning initiatives involving parents and community, and leadership in multi-agency partnerships assisted in situating the research in context.

In essence, the development of FACES projects involved a process of community building among agencies including schools, parents, and children. Block (2009) cites work by a number of theorists (Alexander, 1979; Bornstein, 2004; Erhard, Jensen, \& Zaffron, 2007; Koestenbaum, 1991; McKnight, 1994; Putnan, 2000) on the development 
or restoration of community in American life. Block sees community being developed through a process of possibility-focused conversation involving members of the community to develop vision, purpose, and action.

Early literacy and numeracy initiatives, involving parents and input from the broader community, have long been recognized as beneficial to young children in preparation for positive and successful transitions to school (Heath, 1983; Hill, 1989, Elliott-Johns, 1999; Mustard \& McCain, 1999, 2002; Bouchard, Bender, Poulin-Mackey, \& Letain, 2004; Mustard, McCain, \& Shanker, 2007). The current emphasis on early years education in Ontario, including the introduction of full-day Kindergarten, provides a rich and dynamic context for the FACES project.

Ways to build greater collaboration and shared leadership through school-community, multi-agency partnerships are frequently reflected in the practices of school leaders and teachers who are described as demonstrating confidence and the collective capacity to make improvements (Bryk \& Schneider, 1996, 2002; Claxton, 2002; Noguera, 2003; Fullan, 2005). Significant to such leadership is the ability to model and facilitate implicit "ground rules" for building effective, collaborative relationships. Barkley (2008) identified respect, competence, personal regard, and integrity as key elements for building effective collaborative relationships. Barkley's elements offer guidance for the successful development of multi-agency partnerships and, in turn, provoke questions that appear to shape, tacitly or explicitly, participants' interactions.

The evaluation of the FACES initiative offered opportunities to pursue our earlier work further, and in greater depth. This was significant because Datnow, Hubbard, and Mehan (2002) see multi-agency, integrated services for young children and their families rapidly becoming part of the new policy landscape in education. Recent emphasis in the UK on "multi-agency partnerships" (Cheminais, 2009) contributes to and supports the efficacy of combining community and educational resources in the interests of early learning. Pelletier and Corter (2005) pilot tested an early childhood integrated services model that sought to meet the needs of diverse families in the Toronto region. Their findings clearly underscored the need for teachers to foster and sustain partnerships with families in which the school is the hub of the community.

In summary, there is widespread recognition of the importance of early childhood learning and transitions to school in the development of children, and a movement toward multi-agency partnerships that support families in this regard. Since multiagency partnerships are relatively new in the education landscape, we see it as advantageous to identify potential keys to success. 


\section{Methodology and Methods}

Research was conducted during the development of the three projects and data from individual interviews and focus groups captured participants' thoughts, feelings, and processes experienced over time. Case study and action research methodologies were combined, and the three communities were each treated as a distinct case. The case study approach is ethnographic, thus building a picture of an emerging culture in each case and across cases (Coles, 1989; Sacks, 1985, 1992, 1995; Stake, 2000). Participatory action research was a fundamental strategy that supported the FACES steering committees in ongoing planning, implementation, and review of their respective FACES projects. Following McNiff's (2000) action research cycle, the study monitored and evaluated new directions taken in each community, providing feedback the communities may use to confirm and adjust plans and future actions.

During the spring of 2011, the evaluation process was developed collaboratively with the three community steering committees and TLP. Two cycles of data collection were planned-the first in the Fall 2011 and the second one a year later. Individual and group interviews were conducted with project coordinators, steering committee co-chairs, and steering committee members from the community agencies including school boards. Where local school-based FACES activities had begun, four or five schools were selected, based on their diversity and willingness to participate, and interviews were conducted with each of the school principals, groups of participating educators, community agency representatives, and parents. Data were analyzed to create a picture of FACES development in each of the three communities, and across the communities. This paper reports on results and conclusions from the inception of the projects to December 2011.

The research continued to build on the case study methodology of the earlier study. However, instead of being conducted after completion of the multi-agency project, the current study worked with all three communities during the development and operationalization of their projects.

\section{Discussion of Results}

The results confirm and enrich each of the six keys identified in the earlier study, and a seventh key also emerged: Evidence of Success. 


\section{1) Authentic Community Problem}

Each of the communities decided to enter into the multi-agency project, having identified an authentic community problem related to the well-being of children and their families, early learning, effective transitions to school, and a problem leaders wished to address together. Specifically, the evaluation supported and also added to the previous study in two ways.

First, we found the way the community framed its problem strongly influenced the specific goals and directions of the partnership in that community. For example, one of the communities was motivated by how to improve its low Early Development Instrument (EDI) scores while another was motivated by how to support its marginalized families. Based on differences in the authentic problems they identified, the projects in these two communities developed along very different lines. The former organized around the provision of school-based FACES sessions for parents and their children, and the latter in the development of community-agency-based "hubs," in which schools were only one of a number of partners.

Second, there was evidence that, despite superficial agreement among the various participants on "what the problem was," there were often multiple, tacitly held interpretations of the problem and how it might best be addressed. It therefore took time and substantial effort, particularly within the steering committees, to identify different interpretations and perspectives among the community partners, and build understanding and agreement as a basis for sustainable commitment and planning for collective action.

The identification of an authentic community problem provided compelling motivation underlying the establishment of multi-agency projects. For example, there were distinct benefits to devoting substantial time and effort to dialogue around different understandings of the problem, thus building common understandings and agreement.

\section{2) Viable Source of Help}

Results confirm the conclusion from the previous study that community leaders "bought into" the multi-agency partnership with TLP because they regarded the specific project (in this case FACES) as a potentially significant source of help (e.g., resources, ideas, and/or practices) in addressing the authentic community problem they were experiencing. For example, FACES was perceived by many as a source of help because it was an extension of the already-established WTK program-that is, designed to 
enhance transitions to school and the ability of families and community agencies to support those transitions. This study also supported and enhanced our earlier understandings in three ways:

First, the extent to which perceptions of why and how FACES could help were shared within the steering committee had the potential to affect the cohesiveness of the multiagency partnership and commitment by individuals and groups. Again, there was a tangible need for ongoing dialogue around such questions among the partners (and particularly during planning of activities).

Second, the ways in which the steering committee saw FACES helping to address their authentic problem influenced the goals and directions of the emerging project. For example, when FACES was understood as an extension of WTK, initial action was to provide parents and their children with a number of additional school-based sessions like the WTK session held the previous spring. However, interviews in some communities suggested that, as understandings of FACES developed through ongoing dialogue, actions expanded well beyond those initially chosen.

Third, the extent to which local perceptions of FACES coincided with those of TLP provided learning opportunities for both TLP and the partnering community. These opportunities needed to be addressed through dialogue and negotiation at the community level, within TLP as an organization, as well as between these two. Differences in perspective and efforts to resolve them also proved to be valuable sources of learning for TLP, with the potential to re-shape TLP's own understanding of how to promote parent and community engagement in early learning.

Successful projects coalesced around the central organization's initiative (in this case, TLP's FACES) because key leaders saw the initiative as a probable way to address an authentic problem identified by the community. The degree to which this perception was shared among participants could directly affect cohesiveness of the project.

\section{3) Creative Partnerships}

As in the previous study, TLP intended the FACES projects to be creative partnerships rather than a traditional top-down adoption and implementation model. Thus, there was an expectation that FACES would meld TLP goals and resources with local goals and resources to create something that "worked" and was sustainable within the community itself. Steering committees were thus established in each community to 
shape projects and carry them forward. Ongoing project development was facilitated by dialogue across projects and with TLP itself during regularly scheduled meetings of TLP staff with project coordinators.

The current study enhanced the results of the first in two ways. First, the boundaries set by the central sponsoring agency (TLP) might affect local project development. For example, if boundaries are too tight, there may not be enough room for local development; however, if boundaries are too loose, the broader range of possibilities may increase the complexity of local decision-making and inhibit or delay action. The definition of FACES and the goals set by TLP allowed for wide-ranging project development; each of the communities, and TLP, continue to work towards increased understanding of FACES, and how it relates to particular contexts.

Second, as enhanced understandings of the boundaries of FACES were cultivated, decisions and actions evolved. For example, working from their initial understanding of FACES as an extension of WTK, some communities began by supporting schools to provide two or more FACES meetings each year in addition to their earlier WTK meetings. As dialogue about FACES expanded, communities also began to think about creating additional activities and resources.

Over time, steering committee dialogue around the meaning and scope of FACES resulted in a much clearer focus on what FACES might contribute to their work. Participants acknowledged that FACES became a vehicle for mobilizing community responses to perceived needs.

The relationship between the central organization (TLP) and local partners provided substantial scope for knowledge creation (Hannay, Wideman, \& Seller, 2007): Each project meshed the central organization's goals and resources with local goals and resources to create something that worked within the community itself. By association, boundaries set for the projects by the central organization affected local project development. Situations may occur where boundaries are clarified as projects develop, resulting in further evolution of project decisions and actions both centrally and locally.

\section{4) Dedicated Local Leadership}

As in the previous study, participants indicated that the dedication and ability of local leaders was critical to moving projects forward, while the national TLP leaders tended to act in a supportive and advisory role. The nature of strong local leadership clearly demonstrated a direct response to the pressing community problem, including 
the need to identify collaborative goals that led to collective action in partnerships among independent agencies.

We found that leadership took different forms, being situation dependent in each community, and it remains to be seen how different leadership styles will influence the sustainability of FACES initiatives involving independent partnering organizations over time. Leadership was exercised within collaborative contexts that enabled local leaders to negotiate with TLP how their projects could be shaped to meet community needs. Complex and multiple responsibilities within contemporary leadership roles often require clarification and support, and can present challenges if not communicated effectively. However, skillful leaders found ways to navigate such challenges successfully, bridging their individual efforts with partnerships that embraced the expertise and interests of their colleagues and available resources.

Project coordinators played a key role in the development of FACES in each community. They brought with them quite different qualifications and backgrounds (e.g., one was also executive director of one of the community agencies; the other two were independents-one a retired school principal and the other having no previous employment with any of the partners). This rich array of leadership experience clearly shaped and supported the three projects as unique entities within the broadly defined goals of FACES.

While the coordinators' role took a variety of forms in each community, the role tended to demonstrate vision, organizational skills, the ability to mobilize others, and effective communication. Participants frequently mentioned the critical role of the coordinator and attributed their continued involvement in FACES directly to the coordinator's leadership. Success was consistently attributed to the skills and knowledge of the project coordinators-specifically, their ability to "pull it all together," and to motivate the involvement of others.

The importance of shared leadership in steering committees that included diverse and independent community agencies was consistently highlighted. As researchers, this became more evident as we participated in steering committee meetings, FACES events, and interviews. A "nesting" of various leadership/support roles seems inevitable when, for example, early childhood educators, health professionals, social workers, regional managers, and school board personnel are engaged in vibrant discussions as members of a relatively large committee with a clear, common focus. 
Furthermore, strong local leadership combined with collaborative skills and shared across steering committees contributed to promoting and sustaining the developing work in each community. Individual committee members were already well-respected members of the specific agencies with which they worked; thus they were also powerful catalysts for promoting multi-agency partnerships related to FACES. Diverse voices at the table enabled and informed multi-faceted discussion and opportunities to learn from each other about the different sectors, each with its own specific interests and priorities but collaborating for the common good of the community.

\section{5) A Spirit of Collaboration, Generosity, and Support}

Participants noted a spirit of collaboration, generosity, and support for the FACES projects across all the various participating agencies. This spirit made possible collective action for a common purpose as leaders made available existing organizational structures and resources to support the project. Examples of effective collaboration mentioned by participants included: community agencies making representatives available for steering committee work and to plan/lead FACES sessions for parents; internal collaboration among school administrators and educators to organize and host local FACES sessions; and the availability of independent guest presenters from the community for FACES events.

While levels of collaboration varied from agency to agency and were specific to the goals of the individual projects, it is important to note that project activities also made collaborative, community-partnership processes (Furman, 2004) visible to the community. Visible collaboration was consistently cited as highly significant because agencies (including schools) were seen as working together to demonstrate shared support for parental engagement in early learning.

As FACES projects developed, data collection provided rich insights into how the steering committees evolved as teams. This evolution and the accompanying growth in relationships among members became a central characteristic of the work. For example, each committee comprised a diverse group of individuals representing a range of independent community partners, many with their own academic and professional history, qualifications, priorities, knowledge, and expertise. As partnerships progressed, participants described emerging abilities to understand and appreciate each other's organization, roles, and ways of thinking, and their growing comfort in constructively challenging one another's assumptions and thinking to build broader consensus. 
Members described their growing commitment to participating in the projects and appreciation for the emerging synergy in working with others. Accomplishments of project coordinators, steering committee co-chairs, and steering committee members included creating a cohesive, open, and reflective atmosphere conducive to reaching agreement among diverse, voluntary partners on common goals and collective action to achieve them.

A key accomplishment in each community was the gradual development of closer working relationships between school boards and the other community agencies. Surfacing and exploring this issue, either explicitly or tacitly, was reflected in the dialogue and considered a significant accomplishment-although further work needs to be done to draw a larger number of partners in each community into the projects.

Variations in FACES project goals and actions were inevitably derived in part from the approach taken to collective efforts to promote engagement in early learning, and were accompanied by different challenges. For example, school-focused projects had the challenge of fully developing the role of other community agencies; on the other hand, projects that were more community focused had the challenge of developing the role of the schools.

Collective action among participating agencies was facilitated by a spirit of collaboration, generosity, and support that, in turn, assisted in making existing organizational structures and resources readily available to the projects. Inter-agency collaboration was also strengthened as mutual understanding and appreciation developed. The ability to draw participating school boards into closer alliance with other community agencies working with young children was seen as a major accomplishment of the steering committees, and active participation by multiple agencies in project events (e.g., local FACES sessions with parents, children, and educators) made multi-agency partnerships increasingly visible to the public.

\section{6) A Network of Trusting Relationships}

Participants noted that collaboration was achieved through informal actions grounded in trusting relationships among individuals rather than on formal negotiations, contracts, and checklists among agencies. Trusting relationships among individuals and agencies contributed to higher levels of informal collective action among agencies at both steering committee and local school levels. There was increased evidence of shared ownership for FACES within the wider community (educators, community 
agency personnel, and parents), fuller understanding of FACES, and identification and implementation of engagement strategies for young children and their families.

Participants noted that trust thrived as participants collaborated in common cause. Many comments in interview data indicated that work related to FACES had assisted in raising awareness of the efficacy of individuals from multiple agencies working together as community partners. As one participant stated:

We've been used to working in silos but it feels like we're coming to a place... of seeing the "bigger picture"... It's not about who we are and whom we represent, as much as how we may be responsive? How do we best use the collective resources that we currently have?

As in any activity involving a school, the principal's support was recognized as vital to the success of FACES and the value of a visibly supportive principal, who also actively contributes to FACES in collaboration with representatives of other community agencies, cannot be underestimated. In both research studies it was noted that principals facilitated the availability of school resources, arranged release time for teachers, and mobilized educators and community partners to operationalize plans within the schools.

One challenge identified over and again in interviews was the dissatisfaction with frequent turnover of staff within various agencies, including school boards, and the detrimental effect of this on building and maintaining trust, understanding, and agreement. To counteract the impact of staff turnover, dialogue about project values, goals, and actions must be ongoing. Discourse, reflecting implicit "ground rules" for building effective, collaborative relationships, seems to be adopted (whether formally or informally) as a way of working with many different colleagues (Barkley, 2008). In our experience, the nature of discussions at the steering committee table reflected acknowledgement of key elements essential to day-to-day social exchanges in a diverse community of collaborative co-workers.

Evidence in all three projects suggested the emerging recognition and articulation of a "continuum of care" for children and their families based on mutual trust, and the pursuit of viable approaches to engaging multi-agency partners in meaningful ("authentic") ways. One participant said:

It's not just (about) community partners and schools; it really is about us creating a continuum of care and engagement for families from newborn-the engagement of our schools boards, our health units, our specialized services, and our umbrella agencies 
with regard to child care and serving families with any kind of need. It includes the building of trust and the trust transfer between community partners, schools, health units, and (others).

Inter-agency collaborations are often grounded in trusting relationships among individuals. Initially, a multi-agency project may build upon relationships that bridge the agencies and pre-date the project itself. However, trust becomes extended and enhanced as project participants collaborate in common cause and participants are drawn beyond their "silos" into an emerging continuum of care for children.

\section{7) Evidence of Success}

As one of the keys to success in multi-agency partnerships, evidence of success was somewhat overlooked in the earlier North Bay study (Wideman \& Campbell, 2006). The research conducted after the WTK project had been completed and success, in terms of community commitment and participation, was a given. However, it became apparent in the current study that participants in multi-agency partnerships need to see ongoing evidence that their efforts are resulting in movement toward the goals to which they are committed. This supports what Glickman, Gordon, and Ross-Gordon (2009) term participants' belief in attainment - that is, the faith that one's efforts will bring success, without which there is little motivation for collective action toward agreed-upon goals.

Participants saw developments within the steering committees as ongoing evidence of success because those developments laid the foundation for FACES planning and outreach action. Enhancing trust-based, collaborative relationships among independent partners, developing common goals and undertaking collective action, creating processes for actualizing FACES in the communities, and learning from the results of their work have all proven to be fundamental to the FACES projects. Steering committees were able to establish collaborative inquiries into issues affecting parental and community engagement that went beyond talk, to include collective action to address the needs of each community. For example, these inquiries recognized the importance of planning for inclusion of non-traditional families, extended families, new Canadian families, Aboriginal families, marginalized families, economically disadvantaged families, and families of children with learning challenges.

FACES projects resulted in participants moving beyond their individual roles and contexts, toward greater knowledge of, and appreciation for, colleagues in other agencies. Participants themselves reported this development as evidence of success 
(Block, 2009). Bringing FACES participants together in professional learning sessions, to focus on common goals, plan together, and to co-lead events, was also extremely successful in facilitating ongoing collaboration. Effective professional learning events included learning about EDI scores and their implications for community needs; learning about other community agencies and programs; modeling effective leadership; learning from each other; obtaining information about funding and resources; sharing planning templates and exemplars for FACES sessions; and co-planning FACES sessions.

There was ample evidence the efforts that began in the steering committees were extending into the wider communities. It also became evident that FACES sessions were providing a venue for families to become more aware of community resources available to them. As a result, FACES was increasingly regarded as beginning to provide a service in terms of easing access to community support.

Participants increasingly felt that FACES was beginning to provide effective parental education in strategies for supporting their children's early learning.

Over time, accomplishments of the steering committees included being able to grapple with a variety of endemic challenges affecting FACES. These included how to address staff time constraints and the use of funding, and how to engage more families in their children's early education. A continual challenge was how to attract greater numbers of parents to FACES sessions. Various schools tried a number of ways to support family attendance, and there did not seem to be one "magic" formula for success: Busy families needed flexible options to maximize their attendance. Participants mentioned a number of strategies mobilized to attract parents including: providing information about FACES sessions through a variety of community agencies; scheduling sessions at a variety of times; repeating sessions; advertising compelling topics; providing child care during FACES sessions; continuing to create opportunities for parents and their children to experience activities together; and providing multiple invitations to parents in print, via telephone, and through personal contact. One parent said, "Mostly I came because the teachers made a point of asking me. Once you say you're going to do something, you have to do it and I would've felt bad if I hadn't come."

Communities discussed the need to identify variables and appropriate criteria for measuring the impact of their work in the community over the duration of the projects. For example, one participant said, "At this stage, we can't define success solely in terms of how many parents attend a FACES event because schools all begin in different places in terms of parental engagement." FACES was clearly recognized as attempting to address complex and long-standing problems, problems which may well take significant time 
and effort to address in any one community. At the same time, it was recognized that building parental engagement with schools and other agencies in their children's early learning is a complex problem that may take significant time to address optimally.

\section{Conclusions}

Based on the results from the original study examining the North Bay model and the current study of three additional site-based multi-agency partnership projects, we have confirmed and enhanced our understanding of six keys to the success of multi-agency partnerships and added a seventh-evidence of success. Every one of the seven keys plays a vital role in pulling together a network of central (in this case TLP) and independent community agencies to develop and sustain effective collective action by the partners towards effective transitions to school for young children and their families. We believe that attending to the seven keys can assist authentic leaders to assess and strengthen projects as they develop. To recap, the seven keys are:

1. Identifying a common problem as an authentic community priority;

2. Recognizing a particular program or strategy (in this case, WTK or FACES) as a potential source of help to address the priority;

3. Treating the resulting project as a creative, knowledge-creation exercise; involving a central organization (in this case TLP) and community agencies as partners;

4. Ensuring significant scope for dedicated local leadership;

5. Enhancing a spirit of collaboration, generosity, and support for the project among the community agencies including school boards;

6. Enhancing trusting relationships that facilitate flexible and informal inter-agency action;

7. Identifying and celebrating ongoing evidence of success as the project develops.

Observations of the three multi-agency partnerships as they developed confirmed and enhanced two understandings initially identified in the North Bay study. First, we continue to think that while the existence of committed local leadership is identified as one of the seven keys, the quality of leadership emanating from the collaboration between TLP and local agencies played an essential role in the development of all seven keys. In North Bay, it was found that authentic leadership (Begley, 2001) -inclusive, creative, visionary, and responsive to circumstances-was shared among allies devoted 
to a common cause. In the three FACES projects, leadership took different forms (from more directive to more facilitative), being situation dependent in each community. It remains to be seen how different leadership styles will influence the sustainability of projects over time. However, there is substantial evidence that leadership that is shared, builds relationships, creates vision, develops widespread understanding and agreement, and mobilizes resources, contributes to sustainability because it responds to the inherent independence of the partnering organizations and their voluntary participation. Leadership of projects involving a number of independent, voluntarily participating organizations is regarded as requiring a skill set more akin to volunteer co-ordination across agencies than line management within a single agency. Thus, for example, building common understandings and agreement through dialogue appears fundamental to engaging in collective action and preventing partners from "falling away" over time. As one leader explained, "We think that every decision must be made by consensus because it is the only way to ensure agency buy-in and make the FACES project sustainable in the long run."

Second, development of the three FACES projects confirmed and enhanced our conclusion that, in multi-agency partnerships, it is the quality of relationships that makes flexible and effective collaborative action possible. This echoes the conclusion of Couture, Delong, and Wideman (1999) who wrote:

For us the key factor is the trust relationship among the project leaders that enables them to identify and resolve issues that are crucial to the success of the partnership... issues of power and voice are far more likely to be resolved positively within the context of strong collaborative relationships. (p. 9)

We would go further and suggest that the development of relational trust needs to be a priority at all levels of a project because it is a fundamental basis for dialogue that moves participants beyond their "silos" and into a space where multi-agency collaboration is not only possible but can also thrive (Block, 2009). Relational trust has been described as the "connective tissue that binds individuals together to advance education and welfare of students" (Bryk \& Schneider, 2002, p. 45) —and this notion resonated in interview data about the development of working relationships in the steering committees and among schools and community agencies. Bryk and Schneider (2002) identified respect, competence, personal regard, and integrity as critical elements of trust and argued that, when social trust is part of the everyday discourse among school and community partners, it offers a key resource for informing and changing practice. Bryk and Schneider's conclusions about relationships in school communities also reflect our experiences of observing the development of multi-agency partnerships: 
An interrelated set of mutual dependencies are embedded within the social exchanges in any (school) community. Regardless of how much formal power any given role has.... All participants remain dependent on others to achieve desired outcomes and feel empowered by their efforts. (p. 41)

In short, continuing to embed the discourse of relational trust in the ongoing development of energetic, collaborative relationships among the various community partners proved essential to further enhancing efforts in all three communities.

\section{Implications}

Our experience with the three communities supported an earlier assertion (Campbell, Elliott-Johns, \& Wideman, 2010) that multi-agency projects demand the use of synergistic and generally collaborative approaches to what Cheminais (2009) called the "joint planning and delivery of co-ordinated services" (p. 4). Consequently, the leadership approach to such projects certainly must have more to do with partnership, alliance, and an ethic of community (Furman, 2004) than with rank and hierarchy (Datnow, Hubbard, \& Mehan, 2002; Corter, Patel, Pelletier, \& Bertrand, 2008). Furthermore, because they involve autonomous organizations, projects cannot be based effectively on a technical-rational epistemology (Schon, 1983) involving hierarchical structures and adoption/implementation models. The current study may contribute to ongoing efforts to address top-down/bottom-up tensions through improved knowledge of the phenomenology of educational change (Fullan, 2000, 2005; Sharratt \& Fullan, 2009). As Campbell, Elliott-Johns, and Wideman stated in 2010:

The tension between top-down and bottom-up changes may be addressed when central authorities support local initiatives to develop creative solutions to shared problems. For such a process to work, central leaders need to take a partnership stance and, within broadly stated expectations, honour local leadership, collaboration, and decision-making. (p. 7)

One critical contribution of FACES was the provision of support for communities to engage in dialogue regarding community support for early learning. In writing about the creation of community, Block (2009) emphasizes the critical role conversation plays in creating a future different from the past-conversation in which leaders use their social capital-" the quality of the relationships and cohesion that exists among its citizens" (p. 5) "to transform the isolation and self-interest within our communities into connectedness and caring for the whole" (p. 1). 
We believe the seven keys to success described are characteristic of effective approaches to multi-agency partnerships for early learning and successful transitions to school. Our work also supports the assertions of Corter et al. (2008) that because each community is unique, multi-agency partnerships in those communities must be unique as well, and, therefore, that the development of each project must be treated as an opportunity for knowledge creation (Hannay, Wideman, \& Seller, 2007). One-sizefits-all approaches to educational change are inadequate (Sharratt \& Fullan, 2009) and highly effective, authentic, and responsive leaders are needed, leaders who can bring all partners together to create solutions in context.

As Cheminais indicated (2009), and as a direct result of the work reported here, we believe there is a pressing need for more comprehensive understandings of relationship building in multi-agency collaboration, and more effective community partnerships that support early learning. The "Seven Keys to Success" may also provide further insight and inspiration for other communities as they too address issues and challenges in the education of young children and their families.

\section{References}

Alexander, C. (1979). The timeless way of building. New York: Oxford University Press.

Barkley, S. (2008). Relational Trust. Steve Barkley Ponders Out Loud - Blog - (Performance Learning Systems). Retrieved from http:// blogs.plsweb.com/2008/12/relational-trust. html

Begley, P.T. (2001). In pursuit of authentic school leadership practices. International Journal of Leadership in Education 4, 353-366.

Block, P. (2009). Community. San Francisco: Berrett-Koeler.

Bornstein, D. (2004). How to change the world: Social entrepreneurs and the power of new ideas. New York: Oxford University Press.

Bouchard, D., Bender, S., Poulin-Mackey, L., \& Letain, A. (2004). For the love of reading: Books to build lifelong readers. Victoria, BC: Orca.

Bryk, A.S., \& Schneider, B., (1996). Social trust: A moral resource for school improvement. Madison, WI: Wisconsin Center for Educational Research.
Bryk, A., \& Schneider, B. (2002). Trust in schools. New York: Russell Sage Foundation.

Campbell, T., Elliott-Johns, S.E., \& Wideman, R. (2008). Partnerships and priorities: Promoting early learning through a community-based approach. Research report for The Learning Partnership. Retrieved from www.thelearningpartnership.ca

Campbell, T., Elliott-Johns, S.E., \& Wideman, R. (2010). Six keys to success: Promoting early learning through authentic, shared, and responsive leadership. Journal of Authentic Leadership in Education 1(4), 1-8.

Cheminais, R. (2009). Effective multi-agency partnerships: Putting every child matters into practice. London: Sage.

Claxton, G. (2002). Building learning power. Bristol, UK: Henleaze House.

Coles, R. (1989). The call of stories: Teaching and the moral imagination. Boston: Houghton Mifflin.

Corter, C., Patel, S., Pelletier, J., \& Bertrand, J. (2008). The early development instrument 
as an evaluation tool for school-based, integrated services for young children and parents: The Toronto first duty project. Early Education and Development, 19(5), 773-794.

Couture, M., Delong, J., \& Wideman, R. (1999). What we have learned by building a collaborative partnership. International Electronic Journal for Leadership in Learning (IEJLL) (3). Retrieved from http://www.ucalgary. $\mathrm{ca} /$ iejll/.

Datnow, A., Hubbard, L., \& Mehan, H. (2002). Extending educational reform: From one school to many. London: Routledge Falmer.

Elliott-Johns, S.E. (1999). The home handbook: Home \& school literacy partnerships. Prentice Hall Ginn.

Erhard, W., Jensen, M., \& Zaffron, S. (2007). Integrity: Where leadership begins - A new model of integrity. (PDF File of PowerPoint Slides) Barbados Group Working paper No. 07-03. Retrieved from http://ssrn.com/ abstract $=983401$

Fullan, M. (2000). The three stories of education reform. Phi Delta Kappan, April 2000, 581-584.

Fullan, M. (2005). Leadership and sustainability: System thinkers in action. Thousand Oaks, CA: Corwin Press.

Furman, G. (2004). The ethic of community. Journal of Educational Administration, 42(2), 215-235.

Glickman, C. D., Gordon, S. P., \& Ross-Gordon, J. M. (2009). The basic guide to super vision and instructional leadership. Boston: Pearson.

Hannay, L., Wideman, R., \& Seller, W. (2007). Professional learning to reshape teaching. Toronto, ON: Elementary Teachers' Federation of Ontario.

Heath, S.B. (1983). Ways with words: Language, life and work in communities and classrooms. Cambridge, MA: Cambridge University Press.

Hill, M.W. (1989). Home: Where reading and writing begin. New York: Scholastic.

Koestenbaum, P. (1991). Leadership: The inner side of greatness. San Francisco: Jossey-Bass.

McKnight, J., \& Kretzmann, J. (1994). Building communities from the inside out. Chicago: ACTA Publications.
McNiff, J. (2000). Action research in organizations. New York: Routledge

Mustard, J.F., \& McCain, M.N. (1999). Early years study: Reversing the real brain drain. Toronto, ON: Publications Ontario.

Mustard, J.F., \& McCain, M.N. (2002). The early years study, Three years later. Toronto, ON: Publications Ontario

Mustard, J.F., McCain, M.N., \& Shanker, S. (2007). Early years study 2: Putting science into action. Toronto, ON and Vancouver, BC: Council for Early Childhood Development.

Noguera, P. (2003). City schools and the American dream. New York: Teachers College Press.

Pelletier, J., \& Corter, C. (2005, Winter). Toronto first duty: Integrating kindergarten, childcare, and parenting support to help diverse families connect to schools. Multicultural Education, Winter 2005, 30-37.

Putnan, R. (2000). Bowling alone: The collapse and revisal of American community. New York: Simon and Schuster.

Sacks, O. (1985). The man who mistook his wife for a hat. New York: HarperCollins.

Sacks, O. (1992). Tourette's and creativity. British Medical Journal 305, 1515-1516.

Sacks, O. (1995). An anthropologist on Mars. New York: Vintage Books.

Schon, D. (1983). The reflective practitioner: How professionals think in action. New York: Basic Books.

Sharratt, L., \& Fullan, M. (2009). Realization: The change imperative for deepening district-wide reform. Thousand Oaks, CA: Corwin Press.

Stake, R. (2000). Case studies. In N. Denzin \& Y. Lincoln (Eds). Handbook of qualitative research. (2nd ed.), pp. 435-454. Thousand Oaks, CA: Sage.

The Learning Partnership. Retrieved from www. thelearningpartnership.ca

Wideman, R., \& Campbell, T. (2006). The Welcome to Kindergarten Program in the North Bay area: An initial evaluation. Research report for The Learning Partnership. Retrieved from www.thelearningpartnership.ca 


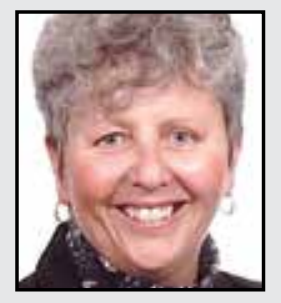

Susan E. Elliott-Johns is an Associate Professor at Nipissing University in the Schulich School of Education, where she teaches pre-service teacher candidates (specifically, courses in language arts and literacy education), and graduate students in education (M.Ed. and Ph.D. programs). Susan's research interests focus on the self-study of teacher education practices (S-STEP), and the development and enactment of pedagogy for teacher education in a changing world. When not reading, writing, and/ or listening to cello concertos, Susan relishes time spent outdoors-especially when working in the garden at her lakeside retreat in Northern Ontario.

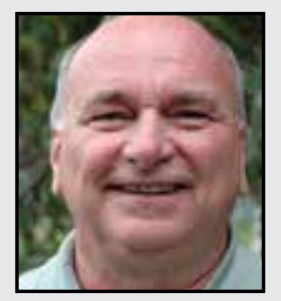

Ron Wideman is Professor of Education at the Schulich School of Education, Nipissing University, Ontario, Canada. Ron has enjoyed a wide-ranging career including years as a secondary school teacher, school-board curriculum co-ordinator, Ontario Ministry of Education official, and university administrator. Ron is an appointed member of the Council of the Ontario College of Early Childhood Educators. He is currently Director of the Nipissing University Centre for the Study of Leadership and Ethics (NUCSLE) and a member of the board of trustees of UCEA's international Consortium for the Study of Leadership and Ethics in Education (CSLEE).

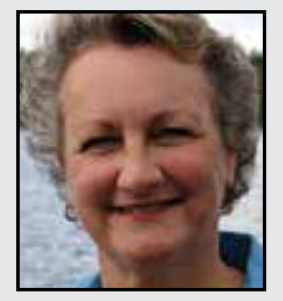

Glenda L. Black is an Assistant Professor at Nipissing University, North Bay, Ontario. In the teacher education program she teaches curriculum courses in teaching and learning and assessment and evaluation. Prior to her joining the Schulich School of Education she was a classroom teacher and school administrator. Glenda is particularly interested in educational leadership, indigenous education, curriculum development, and international teaching practicums. 


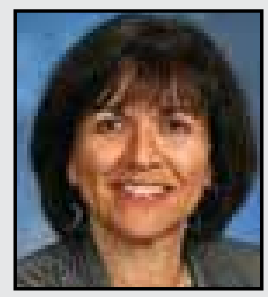

Maria Cantalini-Williams has been an educator for over 30 years, having taught in elementary school, university, and college settings. She has researched and written extensively in the area of early childhood education, reflecting her area of doctoral study and role as a school board program consultant. In the past six years, Maria has served as the Director/Associate Dean of the Laurier-Nipissing concurrent education program, while teaching graduate courses and maintaining her research agenda. Maria is presently the co-principal investigator of four large-scale research grants focused on innovative education practices including mentorship, international teaching, digital technologies, and transitions to school.

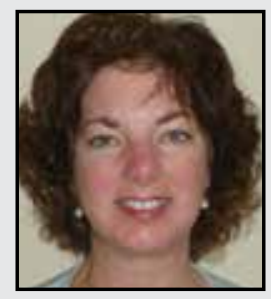

Jenny Guibert has been an educator for over 20 years and has taught with the Toronto and Waterloo Catholic School Boards. She is currently the Early Learning and Kindergarten Instructor at Nipissing University's Schulich School of Education and has established an "Early Learning and Teaching Demonstration Classroom" on campus. Jenny formerly served on the Board of Directors for the Kitchener Our Place Early Years Centre and is presently a member of the Early Years Education Ontario Network. Jenny also provides professional development workshops for teachers in various school boards and Six Nations and facilitates "Early Learning Networking Sessions" for educators involved in the Full Day Early Learning and Kindergarten Program.

\section{LINK TO:}

http://www.nipissingu.ca/about-us/people/Pages/Susan-Elliott-Johns.aspx http://www.nipissingu.ca/about-us/people/Pages/Ron-Wideman.aspx http://www.nipissingu.ca/about-us/people/Pages/Glenda-Black.aspx http://www.nipissingu.ca/about-us/people/Pages/Maria-Cantalini-Williams.aspx http://www.nipissingu.ca/about-us/people/Pages/Jenny-Guibert.aspx http://www.thelearningpartnership.ca http://www.thelearningpartnership.ca/what-we-do/knowledge-mobilization/ research-and-insights/upcoming-research-projects 